\title{
Grand challenges in geomagnetism and paleomagnetism
}

\section{Kenneth P. Kodama*}

Department of Earth and Environmental Sciences, Lehigh University, Bethlehem, PA, USA

*Correspondence: kpkodama@gmail.com

Edited by:

Agust Gudmundsson, Royal Holloway University of London, UK

Keywords: precambrian apparent polar wander, paleozoic geomagnetic polarity timescale, axial geocentric dipole hypothesis, paleosecular variation of the geomagnetic field, magnetoreception, crustal magnetic anomalies, geodynamo modeling

Geomagnetism and paleomagnetism is a broad sub-discipline of the Earth Sciences. I present the Grand Challenges from the perspective of a paleomagnetist and rock magnetist, hence I feel more comfortable with the paleomagnetic side of this short article than the geomagnetic side. Nevertheless, exciting things are happening in geomagnetism and the future is bright for both paleomagnetists and geomagnetists.

In paleomagnetism, one of the important challenges is the extension of accurate apparent polar wander paths back into the Precambrian to facilitate the construction of continental paleogeography deep into Earth's history. In particular, the existence and paleogeography of supercontinents will tell us more about the nature of plate tectonics, and the Wilson cycle, in the Precambrian. Paleomagnetic data have been critical in delineating the supercontinent Pangea from 320-180 Ma. The fragmentation of Pangea has lead to the current configuration of the continents. Critical to investigations of Snowball Earth episodes in the Neoproterozoic (Sturtian from $730-705 \mathrm{Ma}$ and Marinoan from $663-635 \mathrm{Ma}$ ) is the evolution in our understanding of the existence, paleogeography, and fragmentation of the supercontinent Rodinia (900-700 Ma). Rodinia has been built from paleomagnetic data collected from nearly all the continental cratons. The enhanced silicate weathering, and consequent drawdown of $\mathrm{CO}_{2}$ in the atmosphere, caused by the increase of continental margins resulting from the fragmentation of Rodinia, has been suggested to be the cause of Snowball Earth episodes (Hoffman, 1999), showing how important the delineation of supercontinent assembly and fragmentation is to understanding the Earth system through geologic time. More recently evidence is building for a mid-Proterozoic supercontinent, called either Nuna or Columbia (Zhang et al., 2012) from 1.74$1.59 \mathrm{Ga}$. Nuna is built mainly on data collected from Laurentia, Baltica, and the North China block for 1.78-1.40 Ga. Australia adds good data coverage for 1.80-1.60 Ga. Data from the remaining cratons (Amazonia, India, Siberia, Slave) is spotty (Zhang et al., 2012), illustrating the need for more robust apparent polar wander paths in the Precambian. As these ancient apparent polar wander paths are constructed, it will be important to identify and correct the effects of compaction-caused inclination shallowing in sedimentary rocks and the effects of grain-scale strain on the paleomagnetism of deformed rocks that will be almost unavoidable paleomagnetic targets for ancient Precambrian rocks (Kodama, 2012). The challenges for building accurate and well-constrained Precambrian pole paths are great, but ultimately critical to the Earth sciences.

A second grand challenge for paleomagnetists is more definitive understanding of the directional and intensity variations of paleosecular variation of the geomagnetic field through Earth history. A critical, fundamental assumption for using paleomagnetism to reconstruct continental paleogeography is that the Earth's magnetic field has been nearly an axial, geocentric dipole throughout Earth history. Some workers have suggested that significant non-dipole field components, particularly the octupole (e.g., Torsvik and Van der Voo, 2002), have been important components of the geomagnetic field in the Paleozoic and Precambrian. Kent and Smethurst (1998) have shown that a shallow bias in paleomagnetic directions in the
Paleozoic and Precambrian is consistent with a $25 \%$ contribution from an octupolar non-dipole field. However, shallow paleomagnetic inclinations could also be caused by compaction-induced inclination shallowing in sedimentary rocks, so part of the challenge is to tease out accurate paleomagnetic directions from sedimentary rocks as the nature of geomagnetic field behavior is studied into deep time.

If observations of geomagnetic field behavior are limited to the past 5 million years, paleomagnetic data from igneous rocks collected over a wide range of latitudes $\left(78^{\circ} \mathrm{S}-53^{\circ} \mathrm{N}\right)$ do not show similar secular variation behavior of the geomagnetic field either during reversed or normal polarity periods or from the southern and northern hemispheres (Johnson et al., 2008). The 5 million year time period is used because plate motions will not have caused movements greater than several hundred kilometers ( $\sim 250 \mathrm{~km}$ assuming $50 \mathrm{~km} / \mathrm{myr}$ as a typical plate velocity), which is within typical paleomagnetic resolution $\left(\sim 2-3^{\circ}\right.$ and knowing that on the Earth's surface that there is $111 \mathrm{~km} /$ degree of great circle distance). The time-averaged field would deviate more from dipolar behavior in the southern hemisphere during the reversed polarity Matuyama epoch, with a relatively stronger octupolar non-dipole field contribution, than if it were observed from the northern hemisphere during the normal polarity Brunhes epoch. The challenge, then, is to fully document the global behavior of the geomagnetic field over the past 5 million years, and then to push that understanding back in time, to answer the question how far and when the field has strayed from dipolar geometry. 


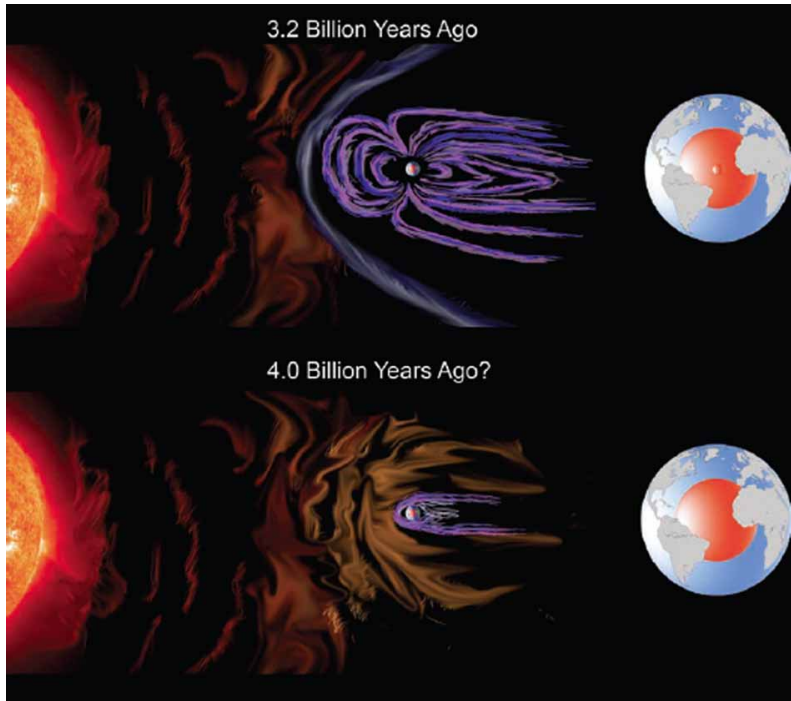

FIGURE 1 | Figure from Tarduno (2009) illustrating the presence of a geomagnetic field at 3.2 Ga based on single crystal absolute paleointensity measurements. Hypotheses based on lunar geochemistry and cooling of the ancient magma ocean suggest no geomagnetic field or a very weak one at $4.0 \mathrm{Ga}$ that would have made the Earth's atmosphere vulnerable to erosion by the solar wind. Diagrams on the right show the outer core and the growth of a small inner core at 3.2 Ga important for a robust geomagnetic field.

A third grand challenge is for paleomagnetists to push the development of the geomagnetic polarity time scale (GPTS) back into the mid to early Paleozoic and the Precambrian. The GPTS is critical to all Earth scientists for dating and correlating sedimentary rock sequences. It is well-calibrated from seafloor magnetic anomalies back to about $170 \mathrm{Ma}$. From $170 \mathrm{Ma}$ to about $200 \mathrm{Ma}$ the GPTS is not continuous and is based on the correlation of terrestrial sequences from England, France, Switzerland, Spain, and Austria (Gradstein et al., 2004). From 199.4$202 \mathrm{Ma}$, the Newark Basin provides an astronomically-calibrated GPTS (Kent and Olsen, 2008). Before $202 \mathrm{Ma}$ the reversals of the geomagnetic field are fairly well-documented by land sequences back into the Carboniferous (Hounslow and Muttoni, 2010; Gradstein et al., 2012; Opdyke et al., in press). Building the GPTS from sedimentary sequences on the continents requires good data coverage and careful work to correlate the sequences independently of the paleomagnetics and to remove the effects of remagnetization on the data. This type of work will be necessary as the GPTS is moved back further in time.

The variability in the reversal rate of the field from about 4-5 reversals/million years in the Neogene and Jurassic to no reversals at all for tens of millions of years during the Permian (300-267 Ma: the Kiaman Superchron) and the Cretaceous (126-84 Ma: the Cretaceous Normal Superchron) provides important information to constrain models of the Earth's geodynamo. More recently evidence is mounting for a third superchron during the Ordovician (480-460 Ma; Pavlov and Gallet, 2005). Extending the GPTS further back in time will be important both for stratigraphic purposes and to better delineate the behavior of the Earth's geodynamo. Part of this challenge would be to increase the time resolution that rock magnetists can offer stratigraphers by further investigation of the rock magnetic records of astronomically-forced global climate cycles. The rock magnetic cyclostratigraphy technique that is being developed offers rock magnetists the ability to provide high resolution chronostratigraphy to Earth scientists for even finer scale dating and correlation ( $\sim 20 \mathrm{kyr}$ resolution; Kodama and Hinnov, 2013).

Extending the record of absolute paleointensity measurements of the geomagnetic field back further in Earth history, beyond the past $400 \mathrm{Ma}$ that includes the majority of absolute paleointensity measurements (Tauxe and Yamazaki, 2007), is another grand challenge for the paleomagnetic and geomagnetic community. The data set of absolute paleointensity data is large, but still $39 \%$ of the data is younger than $1 \mathrm{Ma}$ (Tauxe and Yamazaki, 2007), even though it extends as far back as 3500 Ma. Tarduno (2009) has used single crystal absolute paleointensity measurements to document the strength of the Earth's field at $3.2 \mathrm{Ga}$. This work indicates that the geodynamo had initiated by that time and the geomagnetic field was about $50 \%$ of its current strength (Figure 1). One challenge would be to continue this work to document more precisely when the geomagnetic field switched on, because its presence protects the Earth's atmosphere from the solar wind. Another question that needs to be answered is the relationship between the duration of polarity chrons, particularly superchrons, and the strength of the geomagnetic field. Tauxe and Yamazaki (2007) indicate a weak correlation between field strength and polarity interval length, but more data, both absolute paleointensity data and the geomagnetic reversal time scale needs to be extended back in time, to see if this relationship is supported throughout Earth history. The increase in the absolute paleointensity dataset will also allow a full vector model of the geomagnetic field in distant time, allowing better modeling of the Earth's geodynamo, an important challenge for paleomagnetists and geomagnetists, and its evolution through geologic history.

A larger absolute paleointensity dataset will complement another grand challenge: modeling of planetary and stellar dynamos to understand the full spectrum of dynamo behavior, thus, giving Earth's geodynamo a broader context. Progress has been made in modeling the Earth's geodynamo. Recent numerical modeling of reversal records over the past 40 million years suggests that heterogeneous, rather than homogeneous, heat flow from the core to the mantle increases the reversal frequency of the geomagnetic field (Olson et al., 2010). Furthermore, the total amount of heat flow affects reversal frequency. Superchrons may be the result of overall low global or equatorial heat flow (Olson et al., 2010). The ground truth for constraining the dynamo models can only come from another grand challenge for 
geomagnetists and paleomagnetists, better documentation of the history and characteristics of planetary magnetic fields in the solar system. The development of high spatial resolution magnetic measurements of meteorites and lunar rocks will be one avenue to realize this goal. These measurements can come from new techniques, e.g., scanning SQUID microscopy (Kirtley, 1999; Rochette et al., 2009) and magnetic tunnel junction microscopy (Lima et al., 2013). It will also be important to more completely measure the spatial and temporal characteristics of the current geomagnetic field through satellite missions, similar to the ESA's SWARM that was successfully launched in November, 2013. Making sense of what any satellite magnetic data means for the current geomagnetic field requires understanding high amplitude, large-scale crustal magnetic anomalies and the rock magnetism of their source. Lamellar magnetism (McEnroe et al., 2009) is one possible explanation for the strongest crustal magnetic anomalies on Earth. Its prevalence on Earth and importance to magnetic anomalies on other planets in the Solar System should be another important direction for geomagnetic research.

Finally, it is important to include the field of environmental magnetism, i.e., the use of magnetic minerals to track the movement of materials throughout the Earth system and to understand environmental processes (Thompson and Oldfield, 1986; Evans and Heller, 2003). This sub-discipline of rock magnetism has grown appreciably in the past several decades. Important progress has been made using the magnetics of loess to detect paleoprecipitation variations and of lake, river, and marine sediments to track paleoclimate changes and eolian dust transport. Environmental magnetic measurements have also been used to monitor anthropogenic pollution in the environment. A grand challenge for environmental magnetism is to resolve the ambiguities in tying environmental magnetic parameters to specific environmental or paleoclimate processes (Liu et al., 2012). Environmental magnetism also includes the study of biomagnetism, in which organisms detect the geomagnetic field as one of their tools for survival. One broad, grand challenge that will require collaboration between rock magnetists and biologists is understanding magnetoreception in animals (Walker et al., 2007).

All these topics in geomagnetism and paleomagnetism and many more will be considered for publication in Frontiers in Geomagnetism and Paleomagnetism.

\section{ACKNOWLEDGMENTS}

Kenneth P. Kodama was supported by NSF Grant EAR-1322002.

\section{REFERENCES}

Evans, M. E., and Heller, F. (2003). Environmental Magnetism: Principles and Applications of Enviromagnetics. Amsterdam: Academic Press.

Gradstein, F. M., Ogg, J. G., and Smith, A. (2004). A Geologic Time Scale. New York, NY: Cambridge University Press. doi: 10.4095/215638

Gradstein, F. M., Ogg, J. G., Schmitz, M. D., and Ogg, G. M. (eds.). (2012). The Geologic Time Scale 2012. Oxford: Elsevier.

Hoffman, P. F. (1999). The break-up of Rodinia, birth of Gondwana, true polar wander, and snowball Earth. J. Afr. Earth Sci. 28, 17-32. doi: 10.1016/S0899-5362(99)00018-4

Hounslow, M. W., and Muttoni, G. (2010). The geomagnetic polarity timescale for the Triassic: linkage to stage boundary definitions. Geol. Soc. London Spec. Publ. 334, 61-102. doi: 10.1144/SP334.4

Johnson, C. L., Constable, C. G., Tauxe, L., Barendregt, R., Brown, L. L., Coe, R. S., et al. (2008). Recent investigations of the 0-5 Ma geomagnetic field recorded by lava flows. Geochem. Geophys. Geosyst. 9. doi: 10.1029/2007GC001696

Kent, D. V., and Olsen, P. E. (2008). Early Jurassic magnetostratigraphy and paleolatitudes from the Hartford continental rift basin (eastern North America): testing for polarity bias and abrupt polar wander in association with the central Atlantic magmatic province. J. Geophys. Res. 113. doi: 10.1029/2007JB005407

Kent, D. V., and Smethurst, M. A. (1998). Shallow bias of paleomagnetic inclinations in the Paleozoic and Precambrian. Earth Planet Sci. Lett. 160, 391-402. doi: 10.1016/S0012-821X(98)00099-5

Kirtley, J. R. (1999). Scanning squid microscopy Annu. Rev. Mater. Sci. 29, 117-148. doi: 10.1146/annurev.matsci.29.1.117

Kodama, K. P. (2012). Paleomagnetism of sedimentary rocks: process and interpretation. Oxford: Wiley-Blackwell. 157.

Kodama, K. P., and Hinnov, L. A. (2013). Rock Magnetic Cyclostratigraphy. Oxford: Wiley-Blackwell.

Lima, E. A., Weiss, B. P., Fu, R. R., Suavet, C. R., and Bruno, A. C. (2013). Paleomagnetism on Submillimeter Scales with Scanning Magnetic Microscopy. Eos Transactions of the AGU, Fall 2013 Meeting. (San Francisco, CA), GP43b-07.

Liu, Q., Roberts, A. P., Larrasoana, J. C., Banerjee, S. K., Guyodo, Y., Tauxe, L., et al. (2012). Environmental magnetism: principles and applications. Rev. Geophys. 50. doi: 10.1029/ 2012RG000393

McEnroe, S. A., Fabian, K., Robinson, P., Gaina, C., and L. L. Brown. (2009). Crustal magnetism, lamellar magnetism and rocks that remember. Elements 5, 241-246. doi: 10.2113/gselements.5.4.241

Olson, P. L., Coe, R. S., Driscoll, P. E., Glatzmeier, G. A., and Roberts, P. H. (2010). Geodynamo reversal frequency and heterogeneous core-mantle boundary heat flow. Phys. Earth Planet. Inter. 180, 66-79. doi: 10.1016/j.pepi.2010.02.010

Opdyke, N. D., Giles, P. S., and Utting, J. (in press). Magnetic stratigraphy and palynostratigraphy of the Mississippian-Pennsylvanian boundary interval in eastern North America and the age of the beginning of the Kiaman. Bull. Geol. Soc. Am.

Pavlov, V., and Gallet, Y. (2005). A third superchron during the Early Paleozoic. Episodes 28, 78-84.

Rochette, P., Weiss, B. P., and Gattacceca, J., (2009). Magnetism of extraterrestrial materials. Elements 5, 223-228. doi: 10.2113/gselements.5.4.223

Tarduno, J. A., (2009), Geodynamo history preserved in single silicate crystals: origins and longterm mantle control. Elements, 5, 217-222. doi: 10.2113/gselements.5.4.217

Tauxe, L., and Yamazaki, T. (2007). "Paleointensities," in Treatise on Geophysics. Vol. 5, (Amsterdam: Elsevier), 509-563. doi: 10.1016/B978-0444527486.00098-5

Thompson, R., and Oldfield, F. (1986), Environmental Magnetism. London: Allen and Unwin. doi: 10.1007/978-94-011-8036-8

Torsvik, T. H., and Van der Voo, R. (2002). Refining Gondwana and Pangea palaeogeography: estimates of Phanerozoic non-dipole (octupole) fields. Geophys. J. Inter. 151, 771-794. doi: 10.1046/j.1365-246X.2002.01799.x

Walker, M. M., Diebel, C. E., and Kirschvink, J. L. (2007). "Magnetoreception," in Sensory Systems Neuroscience: Fish Physiology, Vol. 25, eds T. Hara and B. Zielinski (Amsterdam: Elsevier Inc), 335-374.

Zhang, S., Li, Z.-X., Evans, D. A. D., Wu, H., Li, H., and Dong, J. (2012). Pre-Rodinia supercontinent shaping up: a global synthesis with new paleomagnetic results from North China. Earth Planet. Sci. Lett. 353-354, 145-155. doi: 10.1016/j.epsl.2012.07.034

Received: 24 October 2013; accepted: 19 November 2013; published online: 04 December 2013.

Citation: Kodama KP (2013) Grand challenges in geomagnetism and paleomagnetism. Front. Earth Sci. 1:3. doi: 10.3389/feart.2013.00003

This article was submitted to Geomagnetism and Paleomagnetism, a section of the journal Frontiers in Earth Science.

Copyright $(0) 2013$ Kodama. This is an open-access article distributed under the terms of the Creative Commons Attribution License (CC BY). The use, distribution or reproduction in other forums is permitted, provided the original author(s) or licensor are credited and that the original publication in this journal is cited, in accordance with accepted academic practice. No use, distribution or reproduction is permitted which does not comply with these terms. 